\section{OS ARQUITETOS DA POLI: ENSINO E PROFISSÃO EM SÃO PAULO}

Sylvia Ficher

São Paulo: Fapesp; Edusp, 2005.

\section{Eloísa Petti Pinheiro \\ PPG-AU/FAUFBA}

No momento em que se discutem a reforma universitária no Brasil e os novos currículos das faculdades de Arquitetura, onde novas tecnologias surgem revolucionando o ensino e a forma de fazer arquitetura, muito gratificante é poder conhecer a história da formação desse ensino no Brasil, em específico em São Paulo, como é o caso do presente livro do qual nos propomos a apresentar uma resenha. Sem dúvida, um desafio em razão da quantidade de informações significativas encontradas e dos caminhos e questionamentos que surgem ao ler esse volume, belo e muito bem editado.

Necessário e oportuno, o livro Os arquitetos da Poli: ensino e profissão em São Paulo, de Sylvia Ficher, vem preencher uma lacuna nos estudos da formação profissional do arquiteto, em especial do engenheiro-arquiteto, na primeira metade do século XX no Brasil. Fruto de sua tese de doutorado, após dezesseis anos, esse trabalho traz a público o conhecimento de uma importante parte da formação daqueles que iriam intervir na imagem na paisagem urbana, e não somente São Paulo, uma vez que muitos dos profissionais apresentados por Sylvia exerceram suas atividades em várias cidades no Brasil.

Apesar de também ter pesquisado o curso de engenheiro-arquiteto da Escola de Engenharia Mackenzie e do curso de arquiteto da Escola de Belas Artes de São Paulo, o objeto central do livro de Sylvia Ficher é o curso de engenheiro-arquiteto da Escola Politécnica. Um trabalho empírico com a sistematização de informações relevantes em busca de descobrir um processo histórico singular, que, conforme cita a própria autora (p. 18) visa "uma análise descomprometida de valores coorporativos e/ou apologéticos".
A escolha metodológica recaiu no estudo do desempenho profissional, como mercado de trabalho e regulamentação legal, fazendo, no trabalho, um contraponto entre a formação institucional e a atividade do arquiteto na cidade de São Paulo na primeira metade do século passado.

Dividido em três capítulos - "A consolidação do mercado de trabalho 1894-1917"; "A associação profissional 1916-1933"; e "A divisão da profissão 1934-1947" -, o livro faz um recorrido pela trajetória da formação profissional sempre mantendo a mesma sistemática - uma primeira parte com uma leitura pessoal das informações contidas nas demais seções; uma segunda seção onde se descreve o ensino no curso de engenheiro-arquiteto da Politécnica; a terceira se dedica às biografias profissionais comentadas dos professores; e a quarta, às biografias comentadas dos diplomados.

Partindo da abertura das inscrições para os exames preparatórios necessários à matrícula na Escola Politécnica, anunciados em janeiro de 1894, Sylvia começa sua trajetória sobre a história da formação do curso de engenheiro-arquiteto que, finalmente, institucionaliza o ensino de arquitetura em São Paulo em 20 de novembro de 1894.

$\mathrm{Na}$ primeira parte de cada capítulo a autora faz uma contextualização do período abordado, com destaque para os principais pontos que interferem na formação e atuação profissional, entendendo o período histórico, suas relações econômicas e sociais, além de explorar a legislação que altera regimentos e estatutos do ensino do curso de engenheiro-arquiteto da Escola Politécnica. No primeiro período, de 1894 a 1917, apresenta uma análise da estrutura do curso onde demonstra a influência germânica, inclusive com a adoção do ano letivo europeu, e a característica de unificar o curso fundamental com os cursos especiais. Mas Sylvia aponta também para uma influência da École Polytechnique de Paris no que se refere ao curso fundamental. Porém, diferente dos cursos de Paris e do Rio de Janeiro, onde os arquitetos tinham uma formação integrada ao ensino artístico, em São Paulo o ensino de arquitetura seria uma das especialidades da enge- 
nharia. Assim, citando um dos formados no curso de engenheiro-arquiteto, Archimedes de Barros Pimentel, "éramos formados para sermos bons construtores de arquitetura" (p.26).

Esse período coincide com o crescimento econômico de São Paulo e o crescimento das cidades, o que faz surgir um autônomo negócio da construção (p.28). O crescimento da capital do Estado, com a industrialização e o crescimento demográfico, requereu a modernização administrativa e dos equipamentos urbanos, além da expansão física, o que significou a abertura de novos bairros e a demanda por novas construções. O surgimento, em São Paulo de duas escolas superiores de engenharia - a Politécnica de São Paulo, em 1894, e a Escola de Engenharia do Mackenzie College, em 1896 - e da reforma do Liceu de Artes e Ofícios, em 1895, parece indicar, segundo Sylvia, a difusão de uma ideologia do "progresso" em que uma das vertentes seria a institucionalização da formação técnica (p.29).

As associaçōes profissionais - criação do Instituto de Engenharia em 1916 - e os instrumentos de difusão de idéias são outros pontos abordados pela autora, especialmente no segundo período, que vai de 1916 a 1933. Fundamental para entender a formação profissional é a relação com o mercado de trabalho, o qual se incrementa com a execução de obras públicas e a construção de edifícios públicos em grande escala. Tudo isso se vincula à constituição e ao funcionamento dos órgãos da administração estadual e municipal. Nesse ponto, a autora adverte sobre a dificuldade em entender esse funcionamento em razão das constantes reformas que os órgãos sofriam podendo indicar mais uma falta de ação do que o excesso de dinamismo. Também são analisadas algumas obras particulares, com a apresentação de algumas propostas urbanísticas e arquitetônicas para São Paulo.

As legislações que definem os rumos do ensino superior também são objeto de investigação. Eventos como a criação do Ministério dos Negócios da Educação e Saúde Pública, em 1930, e do seu Conselho Nacional de Educação, em 1931, balizam, por exemplo, o limite temporal do segundo período estudado por Sylvia, uma vez que traz conseqüências imediatas, sendo uma delas a incorporação da Politécnica à Universidade de São Paulo, recém-criada em 1934. Nesse segundo período, a autora se debruça sobre as legislações que formalizam os títulos expedidos pelas escolas de engenharia e sobre o controle do exercício das profissóes de engenheiro, arquiteto e agrimensor, o que leva a embates pela regulamentação das associações profissionais.

Finalmente, no período que se estende de 1934 a 1947, a autora aborda a ampliação do campo de trabalho, incluindo discussões sobre a especificidade da arquitetura, que leva os arquitetos a se definirem por oposição, descolando-se dos engenheiros civis, o que, junto ao surgimento das primeiras escolas dedicadas ao ensino de arquitetura - Faculdade de Arquitetura do Instituto Mackenzie, em 1947, e da Faculdade de Arquitetura e Urbanismo da Universidade de São Paulo, em 1948 -, levará, por fim, à divisão da profissão. Nesse percurso, Sylvia analisa como os escritórios particulares passam a se estruturar a partir da década de 1940 com vários profissionais que se organizam segundo uma divisão interna de trabalho. Também crescem as possibilidades de cargos no governo estadual e municipal com o aumento da demanda por obras públicas, incluindo uma desvinculação entre projeto e construção.

Em relação ao ensino, pontuam-se manifestações isoladas por um ensino independente de arquitetura, que culmina com a implantação de duas faculdades no espaço de um ano. As duas faculdades de arquitetura tinham filosofias diferentes de ensino: Anhaia Melo, muito influenciado pela formação francesa, mais humanista e mais culta, acaba implementando na FAUUSP - que não é apenas uma faculdade de arquitetura, mas também de urbanismo -, uma filosofia que resultou na assimilação da prática urbanística americana e na adoção da estética modernista para o ensino; por sua vez, a formação americana de Christiano Stockler das Neves, diretor da Faculdade de Arquitetura Mackenzie, acabou representando a manutenção dos ideais do ensino beaux-arts francês (p.254). E aqui Sylvia aponta para um novo 
capítulo na história do ensino institucional - o de arquitetura.

A segunda parte de cada capítulo é dedicada ao ensino mais especificamente. A autora, para todo o período analisado, optou pela abordagem do estudo dos regulamentos e da organização das cadeiras e aulas, dos respectivos docentes e dos programas em currículos anuais dos cursos especiais de engenheiro-arquiteto e engenheiro civil, o que permitiu distinguir quais as disciplinas especificamente arquitetônicas, que a seu ver "definem (...) o ensino de arquitetura preconizado pela Politécnica nos diferentes momentos" (p.43). Partindo da composição das disciplinas do curso fundamental, pré-requisito para as duas especializações em análise, onde se estabelece um repertório de noções sobre as ciências exatas, a autora disserta sobre a composição das disciplinas e aulas em cada ano do curso, buscando entender a formação dos arquitetos no período.

A terceira parte analisa os professores responsáveis pelas disciplinas especificamente arquitetônicas, apresentando uma biografia comentada de cada um deles e suas principais atuaçôes profissionais. Com a mesma metodologia, na quarta parte, Sylvia comenta a biografia dos diplomados e sua atuação profissional em São Paulo e em outros estados brasileiros, alguns com reconhecido destaque nacional.

Após recorrer todo esse percurso que a autora apresenta, fica claro o caminho trilhado na formação profissional do engenheiro-arquiteto até a divisão tanto profissional como de ensino que levam à formação específica do arquiteto. Apesar de sua leitura fácil e da sua forma didática de apresentação dos conteúdos, ao final do livro sentimos uma lacuna, a falta de uma amarração entre os três capítulos, alguns comentários finais, mas não há prejuízo para o entendimento global da obra. Por fim, podemos dizer que pela importância do seu conteúdo e pela lacuna que vem a preencher na historiografia, e também pela sua bela edição e a excelente qualidade da publicação, é um livro que não pode faltar na biblioteca daqueles que se interessam pelo ensino da arquitetura e pela formação profissional do arquiteto.

\section{BRASIL URBANO}

Edesio Fernandes

Marcio M. Valença (org.)

Rio de Janeiro: Mauad, 2004.

William E. N. Pereira

UFRN

Brasil urbano se constitui em uma coletânea de artigos de vários pesquisadores brasileiros e estrangeiros. Os artigos foram, inicialmente, publicados na revista inglesa GEOFORUM, no fim do ano de 2001. Posteriormente, foram traduzidos para o português e publicados pela editora Mauad. Composto de onze capítulos, Brasil urbano apresenta dois prefácios - um para a versão em inglês e outro para a brasileira -, escritos pelos organizadores da coletânea. O primeiro traz uma breve apresentação dos debates mais recentes e pertinentes sobre o processo de urbanização. O segundo faz a apresentação dos artigos componentes da coletânea.

O objetivo fundamental da coletânea é apresentar a urbanidade brasileira em sua grande diversidade de aspectos. Com esse objetivo, os organizadores juntaram onze artigos em forma de capítulos, de diversos e renomados pesquisadores, que analisam distintos aspectos da urbanização brasileira.

O primeiro capítulo do livro, de autoria de Ana Cristina Fernandes e Rovena Negreiros, é intitulado de "Desenvolvimento econômico, divisão de trabalho e mudanças na rede urbana brasileira: do desenvolvimentismo ao Plano Real". Nesse artigo, as autoras procuram reunir e discutir as principais transformaçōes existentes entre a divisão social do trabalho e as formas dominantes das atividades produtivas. Com esse intuito, as pesquisadoras buscam, inicialmente, traçar um panorama do processo de urbanização do Brasil. Posteriormente, apresentam a rede urbana brasileira como fruto da integração nacional ocorrida nas últimas décadas. Em seguida, discutem a eficiência econômica e a fragmentação espacial nos anos 1990 no Brasil, ressaltando, especialmente, os efeitos das políticas neoliberais sobre o comércio exterior, a indústria e o emprego. Por fim, dis- 